\title{
Older Women Online: Engaged, Active and Independent
}

\section{Helen Hasan}

Australian Health Services Research Institute,

University of Wollongong

Wollongong Australia

Email: hasan@uow.edu.au

\section{Henry Linger}

Australian Health Services Research Institute, Monash University

Melbourne Australia

Email: henry.linger@monash.edu

\section{Abstract}

Older women in our communities are becoming marginalised through their lack of technical awareness and capability. Digital applications now dominate the way governments, business, communities and even families interact with all of us. As respected elders of our society, women not only need access to services which support their wellbeing as they age, but also have an important role to play in passing on their knowledge and wisdom to new generations. Through digital exclusion, older women often relied on others, particularly their spouses, to transact online activities. As they become carers for their ageing spouse or are widowed, they need to learn to do this for themselves. An action research approach recorded responses of seniors to individualised computer-learning sessions. Our research shows that they can learn digital skills, and this is leading to greater independence and social wellbeing. Everyone benefits as our women elders become digitally included.

Keywords living connected, social wellbeing, economic wellbeing older women, digital devices, internet, digital inclusion. 


\section{Introduction}

As in most developed countries, Australia is facing challenges due to its ageing population (Christensen et al 2009) and, as people age, they may need more assistance to attend to the demands of daily living Seidel et al 2011). At the same time, business, government, community and individuals are transitioning to greater reliance on digital devices and online applications in all aspects of modern life (ADII 2017). Many older citizens, i.e. those over 65 years of age, face challenges in adjusting to demands of the digital age. However, when sufficiently mastered, new forms of digital technologies can provide opportunities for positive ageing (Denvir et al 2014). Indeed, economic and social use of digital technologies can play a useful role in meeting the social and economic challenges posed by the ageing populations.

In reviewing the literature on the use of digital technologies by older people, we have not found any research that addresses gender differences in the factors, needs and desires that motivate the use of digital technology. Having conducted research in this area over several years, we believe that there are significant gender differences and that they are worth investigating.

This paper reports on ways that digital inclusion can meet the specific needs of older women, enabling them to remain more engaged, active and independent as they age. Our message is based on the findings of our research conduction with older computer users in regions south of Sydney in New South Wales. Adopting an ongoing action-research approach we investigate how guided digital technology use can improve the economic, social and emotional wellbeing of older citizens (Hasan and Linger 2016, 2017; Burgess et al 2012).

Paying attention to the wellbeing of older citizens is important. Whether in care or at home, many older citizens are becoming increasingly isolated as they age and are no longer able to get around as they once could (Grenade and Boldy 2008). However, with suitable support and more useable technology, this can change so that participation in online activities and communities can enhance the economic and social wellbeing (Taylor 2011).

The most recent findings of our years of research concern the way that older women in our communities can become increasingly marginalised through their lack of technical, experience, awareness and capability. Life expectancy in Australia for women is 85 years in contrast to 80 for men (Australian Bureau of Statistics 2017). This gender gap means that many women outlive the men on whom they relied to do tasks needing digital skills. Studies have shown that, on average, older Australian women are significantly less digitally included than men (ADII 2017). What is more, women now in their 70s and 80s had less education, less time at work and in lower status positions than men of the same age (Burgess et al 2012).

This paper presents recent research which shows how, with suitable devices and ongoing support, older women who have not previously used a computer can develop the digital capability to undertake many tasks that help them maintain independent living and control over decisions affecting their lives. The alternative is that older women become chronically isolated as they age in an increasingly digitised society. This has significantly detrimental impact on their wellbeing. They become disconnected from family, friends and community with little ability to engage in meaningful activities. They become increasingly dependent on others for assistance in attending to the demands of daily living lowering their self-esteem and dignity (Netten et al 2009).

Our research provides evidence of positive instances where older women are learning to use digital devices and online applications to remain connected to, and engaged in, the community as well as access to stimulating activities online. On the one hand, the research reveals the diverse challenges that women face in developing and maintaining digital capability as they age. On the other hand, it has uncovered the many benefits of participation in online activities and communities that contribute to positive ageing. The capability for connected living through online social engagement has the potential to radically enhance positive ageing and revolutionize the efficacy of the social and economic systems of aged care (Hasan and Linger 2016, 2017; Burgess et al 2012; Alcock et al 2014).

The research results show the importance of taking an individualized approach to meeting the needs of each older novice user who is motivated to learn and the importance of making this learning fun. It also reveals how mastering just one or two digital applications can not only enhance social wellbeing but also enable women to have more control of their lives and have less reliance on help from others. 


\section{Background}

This section of the paper first presents the reasons why many older women over 65 are more digitally excluded than men. Then it summarises evidence of the negative consequences of isolation and the problems women face in access, affordability and capability when it comes to digital technology. Also discussed are the domains of wellbeing that can be improved through appropriate digital inclusion.

\subsection{Factors limiting the Digital Capability of Older Women}

The Australian Digital Inclusion Index (ADII) provides evidence at a population level of differences between the digital inclusion of older men and women (ADII 2017). While the gap between men and women is marginal in younger age cohorts ( 0.8 points for people aged $14-24$ years and 1.0 points for those aged 25-34), it expands to 2.9 points in the 35- 49-year cohort and is greatest amongst those aged 65+.On average, the score for older women on the ADII is 2.0 points below that of men. We note that this score is designed for aggregation so that from our perspective the ADII is not a useful research measure as an individual score and so not appropriate for our research.

A review of the literature revealed several contributing factors are that women currently in their 70s and 80s had fewer opportunities for education than men, spent less time at work and more time at home duties than men of the same age. When they were young, girls were encouraged to leave school as soon as possible, get an office job which they stayed in only until they got married. Men were the bread winners who managed the family financial affairs (Seidel et al 2011). This has meant that many women, who outlive their husband or must care for one who is incapacitated, must learn to manage affairs themselves. What is more, most of the tasks whereby an individual manages their affairs can best be done using online applications where digital skills and capability is required.

\subsection{Problems of Isolation}

It is common for isolation to increase with age. For those still living at home, this can be the result of environmental barriers, such as unsafe neighbourhoods, inaccessible housing and inadequate resources for socializing (Cohen-Mansfield et al 2016). While these issues affect older men and women they are critical for the wellbeing of older women. While the evidence is inconclusive, isolation and loneliness within residential aged-care settings may be even greater than it is for older citizens living in the community due to reduced social support (Grenade and Boldy 2008). Isolation is also associated with boredom and inactivity due to increased lack of mobility; recent losses of family and friends, as well as mental health issues leading to shame and fear (Cohen-Mansfield et al 2016).

Isolation is known to have negative impacts on social and emotional wellbeing that can lead to severe problems such as depression (Luo et al 2012). Of particular concern, are the many studies (Luo et al 2012; Cornwell and Waite 2009; Nikmat et al 2015) that have revealed strong correlation between social disconnectedness and physical and mental wellbeing. Many aged-care policies assume that it is inevitable that older people gradually become mentally inactive and unproductive (Norrie 2012; Perland 2004). However, there is a large body of evidence that remaining active, socially connected and emotionally satisfied is a major contributor to health and wellbeing (Netten et al 2009; Diene and Chan 2011; Hagan et al 2014). The World Health Organisation (WHO 2001) sees active ageing in terms of the health, independence and productivity of older people. Positive and productive ageing can improve social and emotional wellbeing in the best interests of both society and the individual (Kaye et al 2003).

\subsection{Problems of Access, Affordability and Capability.}

Research has identified inequalities of access to online information and services within the older population of contemporary ageing societies (Olsson and Viscovi 2016). Lack of access to digital technology excludes many older people from its benefits. As governments strive to replace conventional service delivery with e-government, many of the older demographic are missing out Choudrie et al 2013). This is also true of access to online banking (Diniz et al 2012). and health information (Heart and Kalderon 2013). In Australia, the government emphasizes the use of online services such as my.gov.au and myagedcare.gov.au which assumes that all citizens should have access to such online services.

There is an assumption among many in the aged-care sector that older women have a limited level of digital literacy and little potential to actively engage online. Studies have found that many older citizens do not have access to digital technologies such as email, Skype, productivity tools and social media, or have the relevant skills to use them (Hakkarainen 2012; Lelkes 2013; Hargittai and Dobransky 2017). It is widely accepted that even well-motivated older people have a range of physical, 
cognitive and motivational traits and computer-awareness that together impact on their potential to develop sufficient skills to use digital technology effectively (Burgess et al 2012). However, some recent research has reported growing acceptance of digital technology by older women (Niehaves and Plattfaut 2013; Zheng et al 2015) where improved technology, such as new tablet computers, is playing a role (Xie and J aeger 2008).

\subsection{Attributes of Wellbeing}

Improving wellbeing of older people is the primary motivation for our research but wellbeing is difficult to quantify. Wellbeing is normally associated with people's experience of their quality of life (QOL) determined by satisfaction with their lives and a sense of personal development in their social context (NEF 2013) and, more recently, the social care-related QOL (SCRQoL). The ASCOT project of community care in the UK (Netten et al 2009) identified seven domains of SCRQoL wellbeing among older adults receiving community care services. Research shows that the first four domains (Accommodation, Personal Cleanliness, Food and Nutrition, Safety) are well served by care packages in the UK, Australia and presumably in other developed countries. The next three higher level domains (Occupation, Control, Social Participation) are not. The biggest gaps between needs and how they are being met lie in the higher-level domains on the right: those of engagement (connecting with people and community), activity (having meaningful and rewarding ways to occupy time) and independence (being in control of life).

The findings of the initial stages of our research indicate that these three domains are where digital inclusion could greatly improve the wellbeing of older people: maintaining their independence, keeping then connected to significant others and finding meaningful ways to spend their time (Hasan \& Linger 2016, 2017). We now explain and justify our research methodology.

\section{Research Methodology}

As noted above, quantitative measures of wellbeing for individual older citizens, using QOL for example, were found to be unsuited to research involving older participants. Similarly, we found no quantitative measure of an individual's digital capability, such as the ADII score, that suited this older cohort. Two very recent quantitative studies (Heo et al 2015; Quintana et al 2018; Szabo et al 2018) have reported general links between internet use on the wellbeing of older people but little detail results from this approach. Previous literature has shown that limited, and even conflicting, results have come from studies that use surveys or experiments with older participants (Hagan et al 2014). For these reasons, the research described in this paper adopted an inductive, qualitative approach where we identify positive outcomes from the online activities and communities in which participants chose to engage.

\subsection{Action Research}

An action research approach (Mathiassen et al 2012; McKay and Marshall 2001) was adopted throughout the project. Action research is a form of applied research that is iterative, rigorous and collaborative, using informed interventions to develop a solution to a practical problem that is of value to the people with whom the researchers are working, while at the same time developing theoretical knowledge of value to a research community (Davison et al 2004).

Our research design involved interventions in the form of computer learning sessions with residents in local aged-care facilities over a period of five years. This had practical benefits for the participants and well as providing qualitative data for our research. We designed and implemented these interventions to enable and encourage the use of digital devices and Internet amongst residents. Our project has involved over 100 participants in six different care facilities and in several other sites. Our initial research design consisted of the provision of computer kiosks in a corner of the aged-care facilities' recreation rooms and the conduct of weekly sessions to help residents, who volunteered, learn to use computers and other digital devices for activities of their choosing. More recently we have been holding similar sessions for senior citizens in regional community centres where participants bring their own mobile devices and the problems they have with them.

The qualitative data was collected and subjected to the collection reduction and display phases recommended by Miles and Huberman (1994) so that conclusions could be derived from the results of the thematic analysis. Data was collected on the impact of our interventions in a manner that other researchers have found appropriate to the circumstances of working with the elderly. We followed the inductive approach of similar research to ours (Xie and Jaeger 2008; $\mathrm{Ng} 2007$ ) combined with 
innovative informal methods of data collection and analysis (Sayago et al 2013; Naumanen and Tukiainen 2007). In our research, data consisted of progress updates and field notes where "observations" and "lessons learned" files were kept in which we recorded activities that were interesting, noteworthy, troubling, surprising, or indicated something that worked well (or not). During our data collection, the data was reduced using thematic network analysis and the resulting thematic networks were displayed using a standard social network analysis tool.

\subsection{The Research Settings}

We have had continuous access to five aged-care facilities, in regional Australia, to conduct interventions over the five-year period of the project. The interventions consisted of the provision of what some called computer kiosks in a corner of their recreation area and help sessions run by the researchers. The first facility had taken a few residents to government-run computer classes in the local town. They had discontinued this initiative as the elderly participants had found that the teachers went too fast and did not have the time or patience to address the needs of the elderly. Additionally, between classes many participants had no devices on which to practice, and those that did have a device had no-one to help them when they encountered problems. Following the insistence of the small group of residents who had participated in those classes, the facility owners approved our project.

Managers at the other facilities noted what was happening at our first facility and asked us to set up similar computer kiosks in their facilities. We had several discussions with a range of stakeholder at all sites about the project design and on data collection. The owners, governors and managers allowed us to proceed provided they did have to pay and that we did not annoy participants with interviews or surveys. Our action research methodology was well received. We were able to continue to run the kiosks with the help of local volunteers and a small amount of research funding from our university.

Over the past year we have opened seven public "drop-in" sites at community centres across our region with support from government funding to continue the work. This has constituted the practice outcomes of our action research.

\subsection{The Interventions}

Our interventions are constructed as one-on-one help sessions where participants bring their own device if they have one or use one provided. They learn what their device can do and how to do whatever that interests them. They are provided with individual assistance with problems as they arise in use. These sessions are run by the researchers and other suitable volunteer instructors. We make considerable effort to create a happy, fun and relaxed environment to make this complex context safefail, time-paced, diverse and tolerant of dissent. In other words, the elderly did what they could with the technology, learnt at their own pace, were able to laugh at their mistakes and, most importantly, set the learning agenda. Moreover, each participant was able to use the devices they felt most comfortable with.

\subsection{Data Collection and Initial Analysis}

Data was collected from the interventions. The researchers and other instructors would observe these sessions and encourage participants to reflect on their activities. All kept notes of what was observed and heard, listening to the voices of participants. In this way extensive qualitative data has been collected from the activities of over 100 participants. Additionally, we would regularly engage in discussion with all stakeholders: facility owners, managers, residents, staff and volunteers who participated, as well as other visitors to the facilities, family and friends of residents. These discussions were also documented and provide alternate voices to those of the direct participants in their sessions.

At regular meetings the researchers analysed their notes and observations and identified emergent themes which were reduced to a generic set by systematic analysis. By the end the second year of the research we reached saturation with no new themes being identified. The results at this stage have been published using vignettes to illustrate the emergent themes of: connection, being occupied, selfsufficiency, self-worth/ esteem, productivity, personal development, being in control, and enjoyment (Hasan and Linger 2016, 2017).

It was at this point we became aware of the research undertaken by the ASCOT team (see above) and realised the similarity of our findings. The themes arising from the research were compared with the ASCOT domains of Occupation, Control, and Social Participation (Netten et al 2009). Table 1 demonstrates the alignment of our research themes with the ASCOT domains. 


\begin{tabular}{ll}
\hline ASCOT Domain & Themes arising from the Research \\
\hline Occupation & being occupied, productivity, personal development \\
\hline Control over daily life & self-sufficiency, being in control \\
\hline $\begin{array}{l}\text { Social participation } \\
\text { and involvement }\end{array}$ & connection, self-worth, enjoyment \\
\hline
\end{tabular}

Table 1Alignment of the Themes with the relevant ASCOT Domains

Following the interest shown in our work we have been encouraged to continue our computer help sessions in aged care facilities and community centres. The sessions have been supported by volunteers with some government and community funding. As researchers we have stayed involved, observing and recording happenings at the sessions whenever possible and analysing the data when the opportunity arises according to the themes identified previously. We also looked for the emergence of new themes and this led us to identify issues that are common to many older women among our participants.

\section{New Findings}

\subsection{Our older Women Participants}

Our participants are older people who choose to come to our computer help sessions for a wide variety of reasons from pure curiosity to assistance with specific problems associated with their use of digital devices. Over the five-year period of the research more women (consistently around 70\%) than men have attended the sessions. In addition to the capability factors mentioned previously, this is also due to the lower self-esteem of older women where technology is concerned and the reluctance of many men to admit that they need help. Another aspect we have observed over the years is that men tend to retain the view of a computer as the large, serious device they used at work whereas women, particularly those who have never used computers, are readily enticed by the touch-screen interface of tablets and iPads.

Consistent with our previous publications we present our findings by summarising our observations as representative stories for each of our identified themes.

\subsection{Stories of Women Representing each Theme}

As mentioned above, the result of our initial two-year study was a list of emergent themes of wellbeing related to digital inclusion as follows: connection, being occupied, self-sufficiency, self-worth/ esteem, productivity, personal development, being in control, and enjoyment. In a previous publication we illustrated each theme with vignettes which summarised our data (Hasan \& Linger 2016, 2017).

What follows are new stories of women among our participants to illustrate these themes in our more recent findings.

Connection: One group of participants we met a few years ago were all women who had migrated to Australian decades ago and settled in the area when their husbands got work in the local steel works. They invited us to give some computer help at a social meeting they held weekly at the local community centre. Most said that they didn't know how to use a computer and probably would never be able to so. We asked how they kept in touch with family in the old country and many said they used Skype. This was when we realised that, with older women, it was important to focus on what people want to do, not on the technology. Learning to use a computer does not interest them but finding ways to be connected to family does. We have since had family members who ask us to help when they have given grandma an iPad and a quick introductory lesson but later find the iPad collecting dusk on top of a cupboard.

Being Occupied: Older people often have plenty of time on their hands and little to do. With a device that suit their individual needs, isolated older women can do something meaningful with their time even when on their own. Many of our female participants are amazed with what they can find just surfing the web. One lady in her 70s had suffered with a life-inhibiting affliction since she was thirteen but had never really understood much about it. We found a reputable medical website and she learnt so much that she wished she had known when she was younger. Many others love to use google maps street view to see what has happened to places where they once lived. Perhaps the most popular activity that older people do online is their family history. Once they have the skills they spend hours working on their family tree. 
Self-sufficiency: One of the comments that most of the older participants make from time to time is their desire to do things for themselves and not have to rely on others. A lady who joined recently said that her husband did everything on the computer to keep them connected with their children and manage all important online documents. However. he was not good at organising all their digital pictures they had which had got into a mess. She wanted to learn enough so she could make sure that all these precious pictures were not lost and in albums that she could access herself.

Self-worth/ esteem: Despite assurances that they had made progress with their computing skills, many of the older women express a view that they are dummies compared with younger people. Unfortunately, this attitude is often reinforced by ageist comments from others. Our interventions endeavoured to engender a sense of accomplishment when participants mastered some aspect of the digital world. One example where this was particularly effective was a resident in an aged care facility who was younger than other residents; being in her $60 \mathrm{~s}$. Her need for care was debilitating obesity and she had no family or friends to act as caregiver. She never had visitors and had very low self-esteem. She was relatively computer savvy but could not afford a computer or internet access. Participating in the research, she borrowed one of the iPads the research provided and enrolled in several online courses on various topics. As her confidence grew, she began to attend some of the weekly kiosk sessions and was pleased when other residents asked for her help.

Productivity: Many of our older participants write very well. One former school principle who came to our sessions at one aged-care facility wrote beautiful poems and short stories. With some basic instruction, she learnt to use a word processor to produce a nicely formatted collection that she gave to her grandchildren. This brought them together and the grandchildren reciprocated with stories of their own. This encouraged other residents to do the same. Some even published their efforts online.

Personal Development: A few participants discovered massive, open, online courses (MOOCs) and arranged a program of online courses on topics of interest that they previously had no time or opportunity to study. One lady resident at a multicultural aged-care village had become friends with another lady who came from Spain. Like many people for whom English is a second language, this lady was losing her English language skills as she aged and resorted to her native Spanish. The first lady wanted to learn some Spanish to speak with her friend and we found an online program that helped her do this.

Being in control: Many participants struggled to deal with the confusing array of services that influence their lives such as banking and social security. One participant is not very mobile and has left all such matters to her husband who had died recently. She does not have any close family or friends that she can really trust to manage her affairs. In the kiosk sessions she had learnt to do many of her affairs online. She could check her bank account, pay bills and do other transactions. She felt more in control and is no longer worried that others may be taking advantage of her position.

Enjoyment: Entertainment is provided for residents in aged care but there is not a great deal of variety. Residents argue about which channel to watch on the community TV or which movies to show. Access to streamed entertainment on individual devices gets around this limitation and provides access to many forms of entertainment. The ABC's iView and SBSonDemand are particularly popular. In addition, a couple of women who came to the weekly sessions expressed their desire to travel but they could not afford to do so. They continued to come to the kiosk sessions in order to surf the Internet together and plan where they would go if they could. They loved to do virtual tours of towns, museums, historic sites and gardens all over the world.

\section{Practical Support for the Digital-Inclusion of Older Women}

Action research has outcomes that are both theoretical and practical. The theoretical research outcomes have been published (Hasan and Linger 2016, 2017) providing in depth understanding of the processes involved as older people develop the capability to use digital for their social wellbeing. The research provides insights that can inform others who want to set up similar practical programs in their aged-care facilities. These insights have been incorporated into a practical community service in our region called Living Connected which is now being provided for older people who want to set up and use computers and other digital devices at home. Based on the research findings, the guidelines for this practical service include the following:

1. Focus on an activity that is important to the user not on the technology. The home service begins with a discussion on what the older person wants to do or on what is getting harder to do as they age. With women this is particularly important as it relegated the technology to the background. Families often make the mistake of giving older members a device with a quick overview 
and expect them to use it without any discussion on what they would want to use it for. Our service turns this around so that learning to use a device happens as a by-product of doing something else that is meaningful for the user.

2. Get the right technology for the individual and what they want to do: We don't ignore the technology altogether. Many older people already have a computer or have access to one. They may just need to have it set up and be provided with help to learn to use it for what they want and need. If they don't have a computer, or have one that is not suitable, maybe they need advice on what would be suitable and within their budget. Research has shown that internet use among older people has increased with the popularity of tablet devices (Tsai et al 2014). Women, who have never used computers, can often learn to use a tablet easier than a man for whom a computer, as experienced at work, is a device in a large box with a keyboard and screen.

3. Get connected to the Internet: This is where many older citizens need most help and advice. There is increasingly free WIFI in public places and even some aged-care facilities. There are different home options that vary in price and suitability. Older citizens need someone trustworthy and reliable to help them find the right option for them. The increasing popularity of smart phones has meant that many older women can use these as their Internet connection. However, many take some time to realise the difference between their phone data and a connection to the internet via Wi-Fi.

4. Simple introductory lessons. We have found that most women using a digital device for the first time should focus on something identified in step 1 above that engages them such as playing a game, doing some web surfing, taking a photo, typing some text into a word processor or using Google maps. Some basic computing skills are picked up along the way. Once they have mastered just one thing that they find interesting or fun, they are motivated to learn more of the basic computing skills they need to go further.

5. Provide ongoing help as needed: Every beginner will inevitably need some way to get appropriate ongoing help if they get stuck. Most problems can be solved by someone with basic IT skills, plenty of patience and good humour. Each older person that gets started with us needs to find the right person to provide occasional help for them, maybe a family member, neighbour or student on a community service program.

\section{Discussion}

This action research has yielded both academic and practical outcomes. The work has been published in academic journals and has resulted in a practical service to help older people improve their wellbeing using digital devices.

Participants in our study differed in terms of their computer-awareness, skills, and the physical and cognitive constraints that affect their ability to use a digital device. In this paper we have focused on some of the differences between women and men among older members of society. They come with different previous experiences with technology and women are mostly less experienced and less confidence than men. Women had different preferences as what they needed most where use of digital technology could assist. Our interventions helped participants in our programs to gain and extend their capability to the point where they could use digital device and the internet to do things that interested them and enhanced their wellbeing.

Our research findings are based on themes we have identified that illustrate social wellbeing rather than any objective or subjective measure. Our analysis identified the themes, which we illustrated above, as connection, self-worth/ esteem and personal development, productivity, occupation, selfsufficiency, being in control, and enjoyment. We are confident that after five years of research these themes are comprehensive within our cohort although we acknowledge further themes could arise in other cohorts. We believe that these themes align with three of the ASCOT high-level domains, namely (1) social participation and involvement, (2) occupation, and (3) control over daily life (Netten et al 2009).

Within the context of the societal system of aged care, social and economic use of digital technology has the potential to assist in the social wellbeing of older women by keeping them independent and engaged. We observed that older women are less inhibited in admitting they don't know and tend to under play what they do know. Men are more reluctant to admit their problems. Women very appreciative of help and more focussed on what they can do with technology than on the technology itself. 


\section{Conclusion}

The challenge of an ageing population is an extremely significant societal issue in communities everywhere. The social wellbeing of the elderly is a problem that has not had as much attention as medical or economic issues. Our project identified the complexity of this problem domain and revealed that straightforward empirical studies are not feasible. The current population of older women had little exposure to computers during their lives and received less technical education. Now as they outlive men in a digital world, it is important for them to acquires some digital capability to provide them with both economic and social independence and engagement. Significantly, our research identifies an approach to engage with the older women to enhance their ability to remain productive. It provides them with the opportunity to exploit and explore digital devices to meet their economic and social needs. It opens alternate options to wellbeing that are valid and meaningful and, importantly, are compatible with the complexity of productive ageing.

\section{References}

ADII (2017) Measuring Australia's Digital Divide The Australian Digital Inclusion Index 2017 last accessed J uly 2018 from https:/ / digitalinclusionindex.org.au/ the-index-report/ report/

Alcock, C., Burgess, L. \& Hasan, H. (2014). Connecting isolated senior citizens: illustrating the complexity of social information systems development. In H. Hasan (Eds.), Being Practical with Theory: A Window into Business Research (pp. 126-130). Wollongong, Australia: THEORI.

Australian Bureau of Statistics (2017) 3302.0.55.001 - Life Tables, States, Territories and Australia, 2014-2016, last accesses J uly 2018 from http:/ / www.abs.gov.au/

Burgess, L., Hasan, H. \& Alcock, C. (2012) Information Systems for the Social Wellbeing of Senior Australians, Proceedings of ISD2012, Prato, Italy

Choudrie, J., Ghinea, G., \& Songonuga, V. N. (2013). Silver surfers, e-government and the digital divide: An exploratory study of UK local authority websites and older citizens. Interacting with Computers, http://iwc.oxfordjournals.org/content/ early/2013/02/ 06/iwc.iws020.ful

Christensen, K., Doblhammer, G., Rau, R., \& Vaupel, J . W. (2009). Ageing populations: the challenges ahead. The Lancet, (Vol 374 No 9696 pp 1196-1208).

Cohen-Mansfield, J., Hazan, H., Lerman, Y., \& Shalom, V. (2016). Correlates and predictors of loneliness in older-adults: a review of quantitative results informed by qualitative insights. International Psychogeriatrics, 28(04), 557-576

Cornwell, E \& Waite, L (2009) Social Disconnectedness, Perceived Isolation, and Health among Older Adults, J ournal of Health and Social Behavior (Vol 50 No 1 pp 31-48).

Davison, R. M., Martinsons, M. G., \& Kock, N. (2004). Principles of Canonical Action Research, Information Systems J ournal (Vol 14 No $1 \mathrm{pp}$ 65-86).

Denvir C., J . Balmer N.J . \& Pleasence P. (2014). Portal or pot hole? Exploring how older people use the 'information superhighway' for advice relating to problems with a legal dimension. Ageing and Society, 34, pp 670-699 doi:10.1017/S0144686X12001213

Diene, E. \& Chan, M. (2011) Happy People Live Longer: Subjective Well-Being Contributes to Health and Longevity, Applied Psychology: Health and Well-Being 1-43).

Diniz, E., Birochi, R., \& Pozzebon, M. (2012). Triggers and barriers to financial inclusion: The use of ICT-based branchless banking in an Amazon county. Electronic Commerce Research and Applications, 11(5), 484-494.

Grenade, L. \& Boldy, D. (2008). Social isolation and loneliness among older people: issues and future challenges in community and residential settings. Australian Health Review, 32(3), 468-478

Hagan, R., Manktelow, R., Taylor, B. \& Mallett, J . (2014) Reducing loneliness amongst older people: a systematic search and narrative review. Aging \& Mental Health, (Vol 18 No 6 pp 683-693).

Hakkarainen P (2012) No good for shovelling snow and carrying firewood': Social representations of computers and the internet by elderly Finnish non-users, New media and Society, 14(7) 11981215. 
Hargittai, E., \& Dobransky, K. (2017). Old Dogs, New Clicks: Digital Inequality in Skills and Uses among Older Adults. Canadian J ournal of Communication, 42(2).

Hasan H. \& Linger H (2017) Connected Living for Positive Ageing, in Steven Gordon ed."Online Communities as Agents of Change and Social Movements." pp 203-223

Hasan H. \& Linger H (2016) Enhancing the wellbeing of the elderly: Social use of digital technologies in aged care , J ournal of Educational Gerontology, 42/ 11 749-757

Heart, T., \& Kalderon, E. (2013). Older adults: are they ready to adopt health-related ICT?. International journal of medical informatics, 82(11), e209-e231

Heo, J., Chun, S., Lee, S., Lee, K. H., \& Kim, J. (2015). Internet use and well-being in older adults. Cyberpsychology, Behavior, and Social Networking, 18(5), 268-272.

Kaye, L. Butler S. \& Webster N. (2003) Towards a Productive Ageing Paradigm for Geriatric Practice, Ageing International (Vol 28 No 2 pp 200-213).

Lelkes, O. (2013) Happier and less isolated: internet use in old age, Journal of Poverty and Social Justice(Vol 21 No 1 pp 33-46).

Luo, Y., Hawkley L., Waite L., \& Cacioppo, J . (2012) Loneliness, health, and mortality in old age: A national longitudinal study, Social Science \& Medicine, (Vol 74 NO 6 pp 907-914).

Mathiassen, L., Chiasson, M., \& Germonprez, M. 2012. Style Composition in Action Research Publication. MIS Quarterly, 36(2), 347-363.

McKay J \& Marshall P (2001) The dual imperatives of action research, Information Technology and People, 14(1) 46-59.

Miles MB and Huberman AM 1994 Qualitative Data Analysis, 2nd Edition, Thousand Oaks, CA, Sage Publications.

Naumanen M. \&Tukiainen M. 2007 Guiding the Elderly into the use of Computers and Internet lessons taught and learnt IADIS International Conference on Cognition and Exploratory Learning in Digital Age (CELDA 2007)

NEF (2013) Social Indicators: Individual Retrieved September 302013 from http:// www.proveandimprove.org/ meaim/individuals.php

Netten, A., Burge P., Malley J ., Potoglou N. Brazier, J . Flynn T. \& Forder J . (2009) Outcomes of Social Care for Adults (OSCA): Interim Findings, PSSRU Discussion Paper 2648 2, Retrieved October 10 from http// :www.PSSRU.ac.uk

$\mathrm{Ng}, \mathrm{C} . \mathrm{H}$. (2007). Motivation among older adults in learning computing technologies: A grounded model. Educational Gerontology, 34(1), 1-14.

Niehaves, B. \& Plattfaut, R. (2013) Internet adoption by the elderly: employing IS technology acceptance theories for understanding the age-related digital divide. European J ournal of Information Systems, (Vol 23 No 6 pp 708-726.

Nikmat, A., Hawthorne, G. \& Al-Mashoor, S. (2015) The comparison of quality of life among people with mild dementia in nursing home and home care-a preliminary report Dementia (Vol 14 No $1 \mathrm{pp}$ 114-125).

Norrie, J. (2012) Loneliness on the rise as our cities atomise. Retrieved October 102013 http:// theconversation.edu.au/loneliness-on-the-rise-as-our-cities-atomise-6068

Olsson, T., \& Viscovi, D. (2016). Remaining divides: Access to and use of ICTs among elderly citizens. Politics, Civil Society and Participation: Media and Communications 273 http:// www.researchingcommunication.eu

Perland, D. (2004) European and Canadian studies of loneliness among seniors. Canadian J ournal on Aging. (Vol 23 No 2 pp 181- 188).

Quintana, D., Cervantes, A., Sáez, Y., \& Isasi, P. (2018). Internet use and psychological well-being at advanced age: evidence from the English Longitudinal Study of Aging. International journal of environmental research and public health, 15(3), 480 
Sayago, S., Forbes, P., \& Blat, J. 2013. Older people becoming successful ICT learners over time: challenges and strategies through an ethnographical lens. Educational Gerontology, 39(7), 527544.

Seidel, D., Brayne, C. \&J agger, C. (2011). Limitations in physical functioning among older people as a predictor of subsequent disability in instrumental activities of daily living. Age and Ageing, Retrieved October 102013 from doi: 10.1093/ageing/ afr054

Szabo, A., Allen, J., Stephens, C., \& Alpass, F. (2018). Longitudinal Analysis of the Relationship Between Purposes of Internet Use and Well-being Among Older Adults. The Gerontologist.

Taylor, A. (2011) Social Media as a Tool for Inclusion, Research Report, Canada.

Tsai, H. Y. S., Shillair, R., \& Cotten, S. 2014. Social Support and 'Playing Around': An Examination of How Older Adults Acquire Digital Literacy with Tablet Computers. In 2014 TPRC Conference Paper.

UN (2018) Empowering women in the digital age WHERE DO WE STAND? UN Commission on the Status of Women 14 March NYC

WHO (2001) Active ageing: From evidence to action. Geneva, World Health Organization.

Xie, B. \& J aeger, P. (2008) Computer training programs for older adults at the Public Library. Public Libraries. Sept/ Oct 2008: pp 52-59.

Zheng, R., Spears, J., Luptak, M. \& Wilby, F. (2015) Understanding Older Adults' Perceptions of Internet Use: An Exploratory Factor Analysis, Educational Gerontology, (Vol 41 No 7 pp 504518).

Copyright: (C) 2018 Helen Hasan. This is an open-access article distributed under the terms of the Creative Commons Attribution-NonCommercial 3.0 Australia License, which permits non-commercial use, distribution, and reproduction in any medium, provided the original author and ACIS are credited. 